\title{
An assessment of the ocular tear film in patients with thyroid disorders
}

This article was published in the following Dove Press journal:

Clinical Ophthalmology

\author{
Saud A Alanazi' \\ Abdullah A Alomran' \\ Ali Abusharha' \\ Raied Fagehi' \\ Naji J Al-Johani \\ Gamal A El-Hiti' \\ Ali M Masmali' \\ 'Cornea Research Chair, Department of \\ Optometry, College of Applied Medical \\ Sciences, King Saud University, Riyadh \\ I 1433, Saudi Arabia; ${ }^{2}$ Comprehensive \\ Cancer Center, Department of \\ Endocrinology and Thyroid Oncology, \\ King Fahad Medical City, Riyadh, Saudi \\ Arabia
}

Objective: To investigate the ocular tear film in patients with thyroid disorders using various tests.

Methods: The study involved the assessment of the ocular tear film in 20 patients with thyroid disorders ( 6 men and 14 women) aged 18-43 years (mean \pm standard deviation=34.3 \pm 3.2 years). An age-matched control group consisting of 20 subjects ( 8 males and 12 females) ranging in age from 18 to 43 years $(31.3 \pm 2.9$ years $)$ was also examined under similar conditions. All patients completed the Ocular Surface Disease Index questionnaire, followed by the tear ferning test within the right eye. A phenol red thread test was carried out 10 mins later followed by the fluorescein tear break-up test with a 10-min gap between the tests being implemented.

Results: The median score for the Ocular Surface Disease Index $(P<0.05)$ showed the condition of mild dry eyes [median $(\mathrm{IQR})=15.5(21.9)]$ in patients with thyroid disorders compared to the control group [5.6 (3.6)]. The mean score for the phenol red thread test within both the right and left eyes showed acceptable tear volumes of $11.7 \pm 8.1$ and 10.5 $\pm 7.4 \mathrm{~mm}$, respectively, but this was much lower $(P<0.05)$ compared to those recorded within the control group $(22.2 \pm 6.5$ and $20.7 \pm 5.2 \mathrm{~mm}$, respectively). In addition, the mean for the tear break-up time $(P<0.05)$ scores in both eyes within the patients with thyroid disorders revealed a certain degree of eye dryness $(4.9 \pm 1.6$ and $4.2 \pm 1.9 \mathrm{~s})$, while the control group showed normal eye scores $(13.2 \pm 2.6$ and $12.3 \pm 2.2 \mathrm{~s})$. The median score for tear ferning grades showed eye dryness [2.0 (2.2)] within the study group and normal eyes [1.2 (0.9)] within the control group.

Conclusions: Patients with thyroid disorders have a significant level of eye dryness compared to normal eye subjects.

Keywords: dry eye, thyroid gland disorders, phenol red thread test, tear break-up time test, tear ferning patterns, ocular tear film

\section{Introduction}

Dry eye syndrome is a very common disease of the ocular surface that is caused by various factors. It leads to tear instability due to excessive tear evaporation or a deficiency in tear secretion. The symptoms of eye dryness include eye irritation, excess tearing, discomfort, photophobia, blurred vision, a burning sensation, and redness of the eyes. ${ }^{1,2}$ The tear cycle begins with the tear secretion by the lacrimal gland followed by blinking that distributes the tears over the ocular surface. Finally, tear drainage occurs through the lacrimal puncta or via evaporation. ${ }^{3,4}$ Two main types of dry eye are known, which are, namely, aqueous tear-deficient dry eye and evaporative dry eye. ${ }^{2}$ Aqueous tear-deficient dry eye is caused due to lack of
Correspondence: Saud A Alanazi; Gamal A El-Hiti

Department of Optometry, College of Applied Medical Sciences, King Saud University, P.O. Box 10219, Riyadh II433, Saudi Arabia

Tel +96 6II $4693543 ;+96$ 6II 4693778

Email saaalanazi@ksu.edu.sa;

gelhiti@ksu.edu.sa 
lacrimal secretion and the conjunctiva failing to secrete water, while evaporative dry eye is caused due to certain internal and external causes that serve to accelerate the evaporation of tears. ${ }^{2}$ Disorders in the meibomian gland are the most common internal cause of evaporative dry eye. ${ }^{5}$ Moreover, ocular surface disorders and the wearing of contact lenses are the most common external causes for evaporative dry eye. ${ }^{6}$ Instability in the tear film can lead to dryness since tear film stability depends on several factors, such as tear osmolarity, tear clearance, appropriate blinking, normal lacrimal function, and the maintenance of a normal ocular surface. ${ }^{1}$

There are various tests that can be used to diagnose dry eye along with dry eye questionnaires. Some diagnostic tests are able to detect the quantity of the tears, while others detect the quality of the tears. A combination of tests should be used since there is no single test which can be used for diagnosing the condition of dry eye. ${ }^{7}$ The most common dry eye questionnaire is the Ocular Surface Disease Index (OSDI) [1]. The most common tests used to detect the quantity of tears are the Schirmer test and the phenol red thread (PRT) tests., ${ }^{8,9}$ Incidentally, the tear ferning (TF), tear break-up time (TBUT), tear meniscus height, and osmolarity tests are the most commonly used tests that are employed in order to detect the quality of tears. ${ }^{10-14}$ The treatment of dry eye is very important if the symptoms of eye dryness are to be alleviated in patients suffering from the condition. ${ }^{7}$ Various artificial tears can be used in order to lubricate the eye surface and improve the life quality of patients. ${ }^{7}$ In addition, tears can be preserved by bringing about a reduction in their drainage and via the process of evaporation. The reduction of tears via evaporation can be achieved by increasing humidity in the environment and through avoiding direct air flow as well as the use of oily lubricants. ${ }^{7}$ Moreover, the use of supplementary nutrients such as evening primrose oil and various fish oils may also be beneficial. ${ }^{15}$

The most common types of thyroid disease are hypothyroidism and hyperthyroidism. ${ }^{16,17}$ The corneal sensitivity was reduced during the early signs of thyroid gland disorders. ${ }^{18}$ In addition, confocal microscopy indicated that the nerve fibers in the cornea were low in patients with thyroid disorders compared with normal eye subjects. $^{19}$ Thyroid-associated orbitopathy (TAO), thyroid eye disease, and Graves' ophthalmopathy (GO) are examples of orbital inflammatory conditions that are often associated with dry eye syndrome. Significantly, TAO patients suffer from eye discomfort, redness, irritation, foreign body sensation, and fibrosis in the tissue of the orbit. Annually, TAO occurs in approximately 16 women and 3 men in every 100,000. TAO is common in patients suffering from Graves' disease (80\%), but it is not unusual in hypothyroid patients. ${ }^{20}$ Studies have shown that $45-85 \%$ of the TAO patients have dry eye syndrome. ${ }^{20}$ The widening of the palpebral fissure, exophthalmos, tear production deficiency, and tear evaporation are the main contributing factors for this eye dryness. ${ }^{21-24}$ Several reports have indicated a relationship between thyroid gland disorder and dryness of the eye. ${ }^{25-29}$ In the current study, we report on how the ocular tear film may be assessed in thyroid gland patients in Saudi Arabia as part of our containing research into the assessment of the ocular tear film. ${ }^{30-35}$

\section{Methods}

\section{Subjects}

Twenty patients with thyroid disorders (6 men and 14 women), aged 18-43 years (mean \pm standard deviation $=34.3 \pm 3.2$ years) from Riyadh City participated in the study. The patients represented two types of thyroid disorders as hypothyroidism $(\mathrm{N}=12)$ and hyperthyroidism $(\mathrm{N}=8)$. None of the patients were diagnosed with an autoimmune thyroid disease such as Hashimoto's thyroiditis and Graves' disease or thyroid cancer. Moreover, an age-matched control group consisting of 20 subjects (8 males and 12 females) ranging in age from 18 to 43 years $(31.3 \pm 2.9$ years) was recruited and examined under similar conditions. Any patients with a history of ocular surgery or medications, those demonstrating the recent use of contact lenses, pregnant or breastfeeding women, as well as diabetics and smokers were all excluded from the study. Subjects older than 43 years were excluded since aging (43-86 years) is a known risk factor for eye dryness. ${ }^{36}$ All participants provided written informed consent, and this study was conducted in accordance with the Declaration of Helsinki. Ethical approval (ethics number CAMS-046-3839) for this study was obtained from the College of Applied Medical Science Ethics Committee, King Saud University and King Fahad Medical City. The study itself was conducted at King Fahad Medical City and King Khaled University Hospital, Riyadh. All measurements were carried out by the same examiner under normal conditions. All patients completed the OSDI sheet first, followed by the TF test in the right eye. After 10 mins, the PRT test was performed followed by the TUBT test, which was carried out in both eyes, with a 10-min gap in 
between. The measurements were carried out between the hours of 7:30 am to $3: 30 \mathrm{pm}$. No significant difference in tear quality between measurements was recorded even though the diagnostic tests were carried out at different periods during a single testing session. ${ }^{32}$

\section{Thyroid gland disorder diagnosis}

The diagnosis of thyroid gland disorders was based on the serum thyroid-stimulating hormone (TSH) and free thyroxine (FT4) levels. High levels of TSH and low levels of FT4 indicate hypothyroidism. On the other hand, low levels of TSH and high levels of FT4 indicate hyperthyroidism. ${ }^{37}$ The manufacturer's reference range for TSH is $0.27-4.20 \mu \mathrm{IU} / \mathrm{mL}$. However, the range for FT4 is $12-22 \mathrm{pmol} / \mathrm{L}(0.93-1.7 \mathrm{ng} / \mathrm{dL})$.

\section{OSDI sheet}

An OSDI score of 12 was considered to be an indication of a normal healthy eye, a score of 13-22 was considered to be an indication of a mild dry eye condition, 23-32 was considered to be a sign of moderate dye eye condition, and a score of more than 33 indicated severe eye dryness. ${ }^{38}$

\section{TF test}

A glass capillary tube $(10 \mu \mathrm{L}$, Sigma-Aldrich Chemical Company, UK) was used to collect a tear sample $(1 \mu \mathrm{L})$ from the lower meniscus of the right eye from each subject. The tears were expelled onto a glass slide to dry for 10 mins under normal environmental conditions $\left(23^{\circ} \mathrm{C}\right.$ and a humidity level of less than $40 \%$ ). The TF patterns produced were observed under a digital microscope (Olympus DP72, Tokyo, Japan) with 10×magnifications. The five-point tear ferning grading scale was used to grade the tear ferning patterns using the 0.1 increments in which the cut-off for dry eye is $\geq 2 .{ }^{10}$

\section{PRT test}

PRT strips (Zone-Quick) were purchased from Showa Yakuhin Kako Co, Ltd (Tokyo, Japan). The thread changes color (from a yellow to a light red) when moistened by tears as a result of the change in $\mathrm{pH}$ due to tears. A portion (approximately 3-mm in length) of the thread was folded and inserted one-third of the distance from the temporal canthus of the lower eyelid, with the eye in the primary position. After $15 \mathrm{~s}$, the thread was gently removed and the red-colored portion was measured in millimmeters. The procedure was performed first on the left eye followed by the right eye with a 5-min gap between measurements. ${ }^{30}$ Dry eye was defined for wetting readings less than $10 \mathrm{~mm}$.

\section{TBUT test}

The TBUT test was performed using ProGlo ${ }^{\circledR}$ Fluorescein Strips (Eye Care \& Cure, Tucson, USA). The subject was asked to look down, and a strip was gently touched against the superior conjunctiva. The subject was asked to blink several times and to keep the eye open whilst fixing his/her gaze on a distant target. The time interval between the last blink and the first appearance of dark spots on the precorneal tear film was recorded in seconds. The measurements were taken in both eyes. The cut-off value for dry eye is $<10$ s. $^{39}$

\section{Statistical analysis}

The data were tabulated using Excel (Microsoft ${ }^{\mathrm{TM}}$ Office 2010, Microsoft Corp., Redmond, USA) and was analyzed using the SPSS ${ }^{\circledR}$ statistical package, version 22.0 (SPSS Inc., Chicago, IL, USA) for Windows ${ }^{\circledR}$. A correlation coefficient was used to investigate the relationship between the obtained data. ${ }^{40}$

\section{Results}

Twenty patients with thyroid disorders participated as the study group, and an age-matched control group of 20 patients completed the study. The data were found to be normally distributed (Kolmogorov-Smirnov test; $P>0.05$ ) for the PRT and TBUT scores, and therefore, the mean \pm standard deviation (SD) results were used to represent the average. The data were found to be abnormally distributed (Kolmogorov-Smirnov test; $P<0.05$ ) for the OSDI and TF scores and, therefore, the median (interquartile range) were used to represent the average. The mean $\pm \mathrm{SD}$ values for the PRT and TBUT scores and the median (IQR) for the OSDI and TF scores are shown in Table 1.

The median score for the OSDI $(P<0.05)$ in the study group showed a mild dry eye condition [15.5 (21.9)], while the average score within the control group showed a normal eye condition [5.6 (3.6)]. For the study group, the mean score for the PRT tests within both the right and left eyes showed an acceptable tear volume $(11.7 \pm 8.1$ and $10.5 \pm 7.4 \mathrm{~mm}$, respectively), but this was significantly lower $(P<0.05)$ than the volumes found within the control group ( $22.2 \pm 6.5$ and 20.7 $\pm 5.2 \mathrm{~mm}$, respectively). In addition, the mean for the TBUT scores within the study group showed eye dryness ( $4.9 \pm 1.6$ and $4.2 \pm 1.9 \mathrm{~mm}$ for the right and left eyes, respectively). Normal eyes were indicated from the TBUT scores within the control 
Table I Average [mean \pm standard deviation or median (interquartile range)] for the OSDI, PRTI, PRT2, TBUTI, TBUT2, and TF scores for the study and control groups

\begin{tabular}{|l|l|l|}
\hline \multirow{2}{*}{ Test } & \multicolumn{2}{|l|}{ Average } \\
\cline { 2 - 3 } & $\begin{array}{l}\text { Study group } \\
(\mathbf{N}=\mathbf{2 0}) *\end{array}$ & $\begin{array}{l}\text { Control group } \\
\mathbf{( N = 2 0 )}\end{array}$ \\
\hline OSDI score & $15.5(21.9)$ & $5.6(3.6)$ \\
PRTI (mm) & $11.7 \pm 8.1$ & $22.2 \pm 6.5$ \\
PRT2 (mm) & $10.5 \pm 7.4$ & $20.7 \pm 5.2$ \\
TBUTI (s) & $4.9 \pm 1.6$ & $13.2 \pm 2.6$ \\
TBUT2 (s) & $4.2 \pm 1.9$ & $12.3 \pm 2.2$ \\
TF grade & $2.0(2.2)$ & $1.2(0.9)$ \\
\hline
\end{tabular}

Note: *Statistically significant value at $P<0.05$.

Abbreviations: OSDI, Ocular Surface Disease Index; PRT, phenol red thread; TBUT, tear break-up time; TF, tear ferning; PC, Pearson correlation coefficient; Sig., significance (two-tailed).

group (13.2 \pm 2.6 and $12.3 \pm 2.2 \mathrm{~s}$ for the right and left eyes, respectively). The average score for the TF grades $(P<0.05)$ showed eye dryness [2.0 (2.2)] within the study group and showed normal eye conditions [1.2 (0.9)] within the control group. The side-by-side boxplots for the PRT, TBUT and TF scores within both the study and control groups are shown in

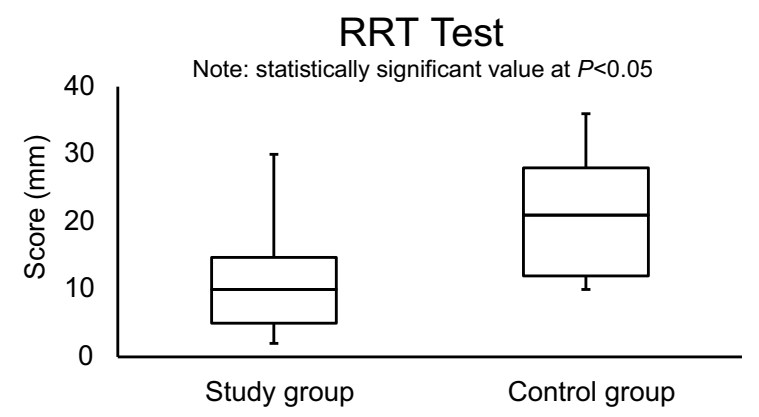

Figure I The side-by-side boxplot for the PRT (OD) within the study and control groups. Statistically significant at $P<0.05$.

Abbreviation: PRT, phenol red thread.

\section{TBUT Test}

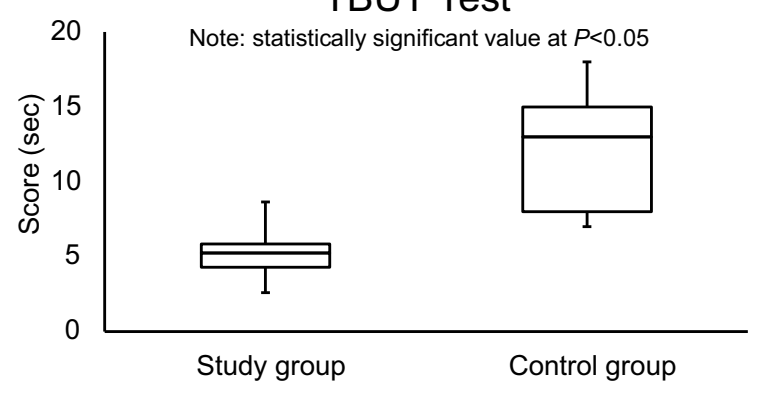

Figure 2 The side-by-side boxplot for the TUBT (OD) within the study and control groups. Statistically significant at $P<0.05$.

Abbreviation: TBUT, tear break-up time.

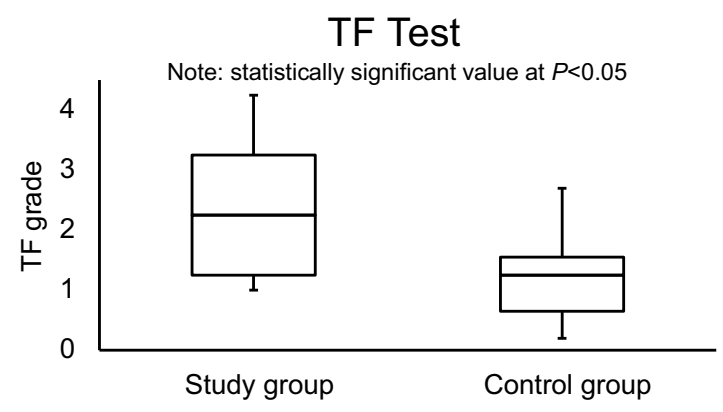

Figure 3 The side-by-side boxplot for the TF test within the study and control groups. Statistically significant at $P<0.05$.

Abbreviation: TF, tear ferning.

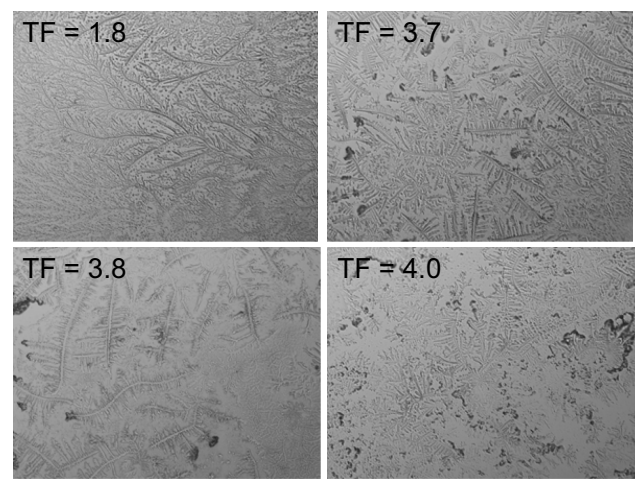

Figure 4 Examples of TF images obtained from the study group (showing dry eye conditions in most cases).

Abbreviation: TF, tear ferning.
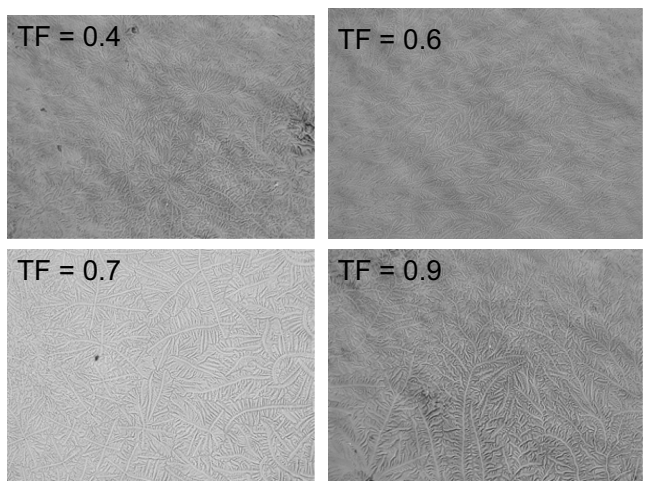

Figure 5 Examples of TF images obtained from the control group (showing normal eye conditions in all cases).

Abbreviation: TF, tear ferning.

Figures 1-3, respectively. Examples of TF images obtained from both the study and the control groups are shown in Figures 4 and 5, respectively.

The correlations between the scores from the various tests carried out within the study group are recorded in Table 2. Generally, the correlations (Mann-Whitney test) between tests were weak since each test corresponds to 
Table 2 Correlation of the OSDI, PRT, TBUT (OD), and TF scores for the study group $(\mathrm{N}=20)^{*}$

\begin{tabular}{|l|l|l|l|l|l|}
\hline \multicolumn{2}{|l|}{ Test/correlation } & OSDI & PRT & TBUT & TF \\
\hline OSDI & PC & I & -0.111 & -0.373 & 0.085 \\
& Sig & - & 0.661 & 0.127 & 0.738 \\
\hline PRT & PC & -0.111 & 1 & 0.371 & 0.023 \\
& Sig & 0.661 & - & 0.130 & 0.927 \\
\hline \multirow{2}{*}{ TBUT } & PC & -0.373 & 0.371 & $I$ & 0.033 \\
& Sig & 0.127 & 0.130 & - & 0.898 \\
\hline \multirow{2}{*}{ TF } & PC & 0.085 & 0.023 & 0.033 & 1 \\
& Sig & 0.738 & 0.927 & 0.898 & - \\
\hline
\end{tabular}

Note: *Statistically significant value at $P<0.05$.

Abbreviations: OSDI, Ocular Surface Disease Index; PRT, phenol red thread; TBUT, tear break-up time; TF, tear ferning; PC, Pearson correlation coefficient; Sig., significance (two-tailed).

a different parameter. The OSDI has a negative weak correlation $(r=0.111)$ with the PRT scores, a positive weak correlation $(r=0.085)$ with the TF grades, and a medium negative correlation $(r=0.373)$ with TBUT scores. The PRT scores have a positive medium correlation with the TBUT scores $(r=0.371)$ and the TF grades $(r=0.023)$.

The patients with thyroid gland disorders $(\mathrm{N}=20)$ were classified as hypothyroidism $(\mathrm{N}=12)$ and hyperthyroidism $(\mathrm{N}=8)$. The mean $\pm \mathrm{SD}$ scores for the PRT and TBUT tests and the median (IQR) scores for the OSDI and TF for both hypothyroidism and hyperthyroidism subjects are shown in Table 3. The TBUT and TF scores showed no significant $(P>0.05)$ differences between hypothyroidism and hyperthyroidism subjects. The OSDI score was significantly $(P<0.05)$ lower in hypothyroidism subjects, while

Table 3 Average (mean \pm standard deviation or median [interquartile range]) for the OSDI, PRTI, PRT2, TBUTI, TBUT2, and TF scores within hypothyroidism and hyperthyroidism subjects

\begin{tabular}{|l|l|l|}
\hline \multirow{2}{*}{ Test } & \multicolumn{2}{|l|}{ Average } \\
\cline { 2 - 3 } & $\begin{array}{l}\text { Hypothyroidism } \\
(\mathbf{N}=\mathbf{8})\end{array}$ & $\begin{array}{l}\text { Hyperthyroidism } \\
\mathbf{( N = 1 2 )}\end{array}$ \\
\hline OSDI score* & $14.3(10.0)$ & $25.8(30.1)$ \\
PRTI (mm)* & $13.5 \pm 9.4$ & $9.4 \pm 5.8$ \\
PRT2 (mm)* & $12.5 \pm 7.0$ & $8.0 \pm 6.6$ \\
TBUTI (s) & $4.3 \pm 1.4$ & $5.4 \pm 1.5$ \\
TBUT2 (s) & $3.9 \pm 1.7$ & $4.5 \pm 1.8$ \\
TF grade & $2.0(15)$ & $2.5(3.0)$ \\
\hline
\end{tabular}

Note: *Statistically significant value at $P<0.05$.

Abbreviations: PRT, phenol red thread; TBUT, tear break-up time; TF, tear ferning; PRTI and TBUTI, the measurements for the right eye; PRT2, the measurements for the left eye; TBUT2, the tears for the TF test were collected from the right eye. the PRT scores were significantly $(P<0.05)$ lower in hyperthyroidism subjects.

\section{Discussion}

The results obtained revealed that patients with thyroid disorders had a significant dry eye level compared to the control subjects. The OSDI score for patients with thyroid disorders was high compared with the score for the control group. The mean score for the PRT test within both the right and left eye for the study group was much lower $(11.7 \pm 8.1$ and $10.5 \pm 7.4 \mathrm{~mm}$, respectively) when compared with the scores observed within the control group $(22.2 \pm 6.5$ and $20.7 \pm 5.2 \mathrm{~mm}$, respectively). Similarly, the mean score for the TBUT test for the study group in both eyes was significantly lower (4.9 \pm 1.6 and $4.2 \pm 1.9 \mathrm{~s}$ ) compared with those obtained within the control group (13.2 \pm 2.6 and $12.3 \pm 2.2 \mathrm{~s})$. The main score for the TF grades showed a level of eye dryness $[2.0(2.2)]$ for the study group, while the main score for the control group showed normal eye conditions $[1.2(0.9)]$. To the best of our knowledge, this is the first time that a TF test was used to assess the quality of tears within patients with thyroid disorders in Saudi Arabia.

The current study showed that the median average for the OSDI score was higher in hyperthyroidism subjects (25.8 [30.1]) compared with hypothyroidism subjects (14.3 [10.0]). While, the main scores for the PRT test within both eyes were higher in hypothyroidism subjects compared with those hyperthyroidism subjects. Similar observations were made before within hypothyroidism and hyperthyroidism subjects. ${ }^{21}$ For example, the average OSDI score was found to be significantly higher in hyperthyroidism subjects [31.0 (28.0)] compared with hypothyroidism subjects $[11.2(11.0)] .^{21}$ While, tear evaporation rate was found to significantly higher in hypothyroidism subjects [53.0 (28.0)] compared with hyperthyroidism subjects $\left[29.0\right.$ (59.5)]. ${ }^{21}$ The high level of dryness within patients with thyroid disorders could possibly be due to inadequate tear production, high tear evaporation, tear film instability, and disturbances within the content of certain proteins within the tear film.

The evaluation and management of GO and TAO patients have been discussed previously. ${ }^{41,42}$ Patients with thyroid disorders tend to suffer from eye dryness as well as significant damage to the ocular surface compared with normal patients. The OSDI scores in TAO patients are noted to be high in comparison with the control 
group. ${ }^{22,24}$ For example, the mean OSDI score recorded in relation to patients with thyroid disorders was higher $(29.0$ \pm 20.8 ) compared with the one recorded for normal eye subjects (13.2 \pm 7.8$){ }^{22}$ The mean score for the Schirmer test within the patients with thyroid disorders was 5.1 $\pm 2.3 \mathrm{~mm}$ compared to $11.4 \pm 3.3 \mathrm{~mm}$ for the control group. $^{22}$ Another study showed that the mean score for the Schirmer test was $14 . \pm 8.3 \mathrm{~mm}$ in patients with thyroid disorders, which is significantly lower than the one recorded within normal eye subjects $(24.9 \pm 3.6 \mathrm{~mm}){ }^{25}$ The mean TBUT scores in the patients with thyroid disorders were found to be $6.8 \pm 3.7$ s compared with $12.7 \pm 1.9$ $\mathrm{s}$ for the control group subjects. ${ }^{22}$ The mean average for the TBUT test was found to be lower within patients with thyroid disorders (5.8-7.1 s) compared with the score recorded within the control group $(10.0-11.4 \mathrm{~s}) .^{22,25-27}$ Moreover, the tear osmolarity was found to be higher in patients with thyroid disorders $(319.0 \pm 17.4 \mathrm{mOsm} / \mathrm{L})$ compared to the control group $(307.9 \pm 12.7 \mathrm{mOsm} / \mathrm{L}){ }^{22}$

Patients with thyroid disorders suffer from exophthalmos that affects the soft tissues of the eye leading to their expansion. $^{43,44}$ Exophthalmos leads to lagophthalmos; a condition which renders an individual unable to fully close their eyelids. This subsequently disturbs the ocular surface and elevates the tear evaporation rate as well as tear hyperosmolarity. ${ }^{4,46}$ In addition, strabismus is common in patients with thyroid disorders as a result of the impairment of the extraocular muscles, which results in head tilt and diplopia. Diplopia usually occurs in patients with thyroid disorders due to the inflammation and swelling of the extraocular muscles. ${ }^{47}$ The most affected extraocular muscles are the inferior rectus and the medial rectus muscles, resulting in vertical and horizontal deviations. Therefore, due to the changes in tear evaporation rate, tear osmolarity, and altered eyelid structure, dry eye syndrome is usually seen in patients with thyroid disorders. ${ }^{47}$ The onset of the various different signs and symptoms of patients with thyroid disorders differs amongst patients. They can be seen simultaneously or take up to several months or years to manifest themselves. ${ }^{48}$

Evidence has emerged to suggest that the ocular inflammation mediated by $\mathrm{T}$ lymphocytes plays a critical role in the pathogenesis of dry eye syndrome by reducing the production of aqueous tears. ${ }^{49,50}$ Patients with thyroid disorders have an abnormality in the proteinaceous composition and protein profile of the tear film, which indicates a dysfunction in the lacrimal gland as highlighted by certain studies. ${ }^{51-53}$ The damage sustained by the ocular surface in patients with thyroid disorders is associated with a reduction in tear production due to the involvement of the lacrimal gland. ${ }^{27}$ In addition, the instability of the tear film results in a shorter tear film breakup time, which is related to palpebral fissure height in patients with thyroid disorders. ${ }^{54}$

\section{Conclusion}

Patients with thyroid disorders were found to have significantly high levels of eye dryness due to factors associated with dry eye syndrome. The mechanism by which such eye dryness occurs is not yet clear, although several factors have been cited including low tear production, excessive tear evaporation, tear instability, and disturbances in the tear film lipid layer. A more detailed study is needed in order to better understand the situation and which factors cause such phenomena to occur. Eye drops and lubricants may possibly help patients with thyroid disorders by reducing their ocular discomfort and by smoothing the ocular surface, thereby providing better vision and relief from such debilitating symptoms.

\section{Acknowledgment}

The project was supported by King Saud University, Deanship of Scientific Research, Research Chairs.

\section{Disclosure}

The authors report no conflicts of interest in this work.

\section{References}

1. The definition and classification of dry eye disease: report of the definition and classification subcommittee of the international dry eye work-shop 2007. Ocul Surf. 2007;5(2):75-92. doi:10.1016/ S1542-0124(12)70081-2

2. Lemp MA. Report of the National Eye Institute/Industry workshop on clinical trials in dry eyes. Clao J. 1995;21(4):221-232.

3. Li M, Du C, Zhu D, Shen M, Cui L, Wang J. Daytime variations of tear osmolarity and tear meniscus volume. Eye Contact Lens. 2012;38 (5):282-287. doi:10.1097/ICL.0b013e31823fdb2a

4. Tomlinson A, Khanal S, Ramaesh K, Diaper C, McFadyen A. Tear film osmolarity: determination of a referent for dry eye diagnosis. Invest Ophthalmol Vis Sci. 2006;47(10):4309-4315. doi:10.1167/ iovs.05-1504

5. Bron AJ, Tiffany JM, Gouveia SM, Yokoi N, Voon LW. Functional aspects of the tear film lipid layer. Exp Eye Res. 2004;78(3):347-360. doi:10.1016/j.exer.2003.09.019

6. Moss SE, Klein R, Klein BE. Incidence of dry eye in an older population. Arch Ophthalmol. 2004;122(3):369-373. doi:10.1001/ archopht.122.3.369

7. Johnson ME, Murphy PJ. Changes in the tear film and ocular surface from dry eye syndrome. Prog Ret Eye Res. 2004;23(4):449-474. doi:10.1016/j.preteyeres.2004.04.003

8. Vitali C, Bombardieri S, Jonsson R, et al. Classification criteria for Sjögren's syndrome: a revised version of the European criteria proposed by the American-European Consensus Group. Ann Rheum Dis. 2002;61(6):554-558. doi:10.1136/ard.61.6.554 
9. van Bijsterveld OP. Diagnostic tests in the sicca syndrome. Arch Ophthalmol. 1969;82(1):10-14. doi:10.1001/archopht.1969. 00990020012003

10. Masmali AM, Murphy PJ, Purslow C. Development of a new grading scale for tear ferning. Cont Lens Anterior Eye. 2014;37(3):178-184. doi:10.1016/j.clae.2013.09.011

11. Rolando M. Tear mucus ferning test in normal and keratoconjunctivitis sicca eyes. Chibret Int J Ophthalmol. 1984;2(4):32-41.

12. Vashisht S, Singh S. Evaluation of phenol red thread test versus Schirmer test in dry eyes: a comparative study. Int J Appl Basic Med Res. 2011;1(1):40-42. doi:10.4103/2229-516X.81979

13. Cho P, Ho K-Y, Huang Y-C, Chui H-Y, Kwan M-C. Comparison of non-invasive tear break-up time measurements from black and white background instruments. Optom Vis Sci. 2004;81(6):436-441.

14. Ibrahim OM, Dogru M, Takano Y, et al. Application of visante optical coherence tomography tear meniscus height measurement in the diagnosis of dry eye disease. Ophthalmology. 2010;117 (10):1923-1929. doi:10.1016/j.ophtha.2010.01.057

15. Caffery BE. Influence of diet on tear function. Optom Vis Sci. 1991;68(1):58-72. doi:10.1097/00006324-199101000-00010

16. Al Shahrani AS, El-Metwally A, Al-Surimi K, et al. The epidemiology of thyroid diseases in the Arab world: a systematic review. J Public Health Epidemiol. 2016;8(2):17-26. doi:10.5897/JPHE2015.0713

17. McPhee S, Hammer G. Pathophysiology of Disease: An Introduction to Clinical Medicine. 7th ed. New York, NY: McGraw-Hill Education; 2014

18. Bartalena L, Wiersinga WM, Pinchera A. Graves' ophthalmopathy: state of the art and perspectives. J Endocrinol Invest. 2004;27 (3):295-301. doi:10.1007/BF03345280

19. Villani E, Viola F, Sala R, et al. Corneal involvement in Graves' orbitopathy: an in vivo confocal study. Inves Ophthalmol Vis Sci. 2010;51(9):4574-4578. doi:10.1167/iovs.10-5380

20. Rizvi SAR, Rana V, Sheelu SS, Maheshwari V, Gupta Y. Dry eye evaluation in thyroid associated orbitopathy. Int $J$ Ocul Oncol Ocul. 2016;2(2):90-94

21. Abusharaha A, Alturki AA, Alanazi SA, et al. An assessment of the tear evaporation rate in thyroid gland patients. Clin Ophthalmol. 2019;13:131-135. doi:10.2147/OPTH.S188614

22. Turkyilmaz K, Öner V, Şahin SB, et al. Tear film osmolarity in patients with Graves ophthalmopathy. Eur J Gen Med. 2014;11 (1):15-19. doi:10.15197/sabad.1.11.04

23. Gupta A, Sadeghi PB, Akpek EK. Occult thyroid eye disease in patients presenting with dry eye symptoms. Am J Ophthalmol. 2009;147(5):919-923. doi:10.1016/j.ajo.2008.12.007

24. Selter JH, Gire AI, Sikder S. The relationship between Graves' ophthalmopathy and dry eye syndrome. Clin Ophthalmol. 2015;9:57-62.

25. Gürdal C, Saraç O, Genç I, Kırımlıŏlu H, Takmaz T, Can I. Ocular surface and dry eye in Graves' disease. Curr Eye Res. 2011;36 (1):8-13. doi:10.3109/02713683.2010.526285

26. Nowak M, Marek B, Kos-Kudła B, Kajdaniuk D, Siemińska L. Tear film profile in patients with active thyroid orbithopathy. Klin Oczna. 2005;107(7-9):479-482.

27. Eckstein AK, Finkenrath A, Heiligenhaus A, et al. Dry eye syndrome in thyroid-associated ophthalmopathy: lacrimal expression of TSH receptor suggests involvement of TSHR-specific autoantibodies. Acta Ophthalmol Scand. 2004;82(3):291-297. doi:10.1111/j.1395-3907.2004.00268.x

28. Gürdal C, Genç I, Saraç O, Gönül I, Takmaz T, Can I. Topical cyclosporine in thyroid orbitopathy-related dry eye: clinical findings, conjunctival epithelial apoptosis, and MMP-9 expression. Curr Eye Res. 2010;35(9):771-777. doi:10.3109/02713683.2010.490320

29. Achtsidis V, Tentolouris N, Theodoropoulou S, et al. Dry eye in Graves ophthalmopathy: correlation with corneal hypoesthesia. Eur J Ophthalmol. 2013;23(4):473-479. doi:10.5301/ejo.5000259

30. Masmali A, Alqahtani TA, Alharbi A, El-Hiti GA. Comparative study of repeatability of phenol red thread test versus Schirmer's test in normal adults in Saudi Arabia. Eye Contact Lens. 2014;40 (3):127-131. doi:10.1097/ICL.0000000000000025
31. Masmali A, Alrabiah S, Alharbi A, El-Hiti GA, Almubrad T. Investigation of tear osmolarity using the TearLab ${ }^{\mathrm{TM}}$ osmolarity system in normal adults in Saudi Arabia. Eye Contact Lens. 2014;40(2):74-78. doi:10.1097/ICL.0000000000000002

32. Masmali AM, Al-Bahlal JM, El-Hiti GA, et al. Repeatability and diurnal variation of tear ferning test. Eye Contact Lens. 2015;41 (5):262-267. doi:10.1097/ICL.0000000000000116

33. Masmali AM, Al-Qhtani S, Al-Gasham TM, El-Hiti GA, Purslow C, Murphy PJ. Application of a new grading scale for tear ferning in non-dry eye and dry eye subjects. Cont Lens Anterior Eye. 2015;38 (1):39-43. doi:10.1016/j.clae.2014.09.007

34. Masmali AM, Al-Shehri A, Alanazi SA, Abusharaha A, Fagehi R, ElHiti GA. Assessment of tear film quality among smokers using tear ferning patterns. J Ophthalmol. 2016;2016:8154315. doi:10.1155/2016/ 8154315

35. Masmali AM, Maeni YA, El-Hiti GA, Murphy PJ, Almubrad T. Investigation of ocular tear ferning in controlled and uncontrolled diabetic subjects. Eye Contact Lens. 2018;44(Suppl 2):S70-S75. doi:10.1097/ICL.0000000000000419

36. Moss SE, Klein R, Klein BE. Long-term incidence of dry eye in an older population. Optom Vis Sci. 2008;85(8):668-674. doi:10.1097/ OPX.0b013e318181a947

37. Kasper D, Fauci A, Hauser S, Longo D, Jameson J, Joseph J. Harrison's Principles of Internal Medicine. 19th. Chapter 405. New York, NY: McGraw-Hill Education Medical; 2015.

38. Ozcura F, Aydin S, Helvaci MR. Ocular surface disease index for the diagnosis of dry eye syndrome. Ocul Immuno Inflamm. 2007;15 (5):389-393. doi:10.1080/09273940701486803

39. Bekibele CO, Baiyeroju AM, Ajaiyeoba A, Akang EE, Ajayi BG. Case control study of dry eye and related ocular surface abnormalities in Ibadan, Nigeria. Int Ophthalmol. 2010;30(1):7-13. doi:10.1007/ s10792-008-9281-8

40. Cohen J. Statistical Power Analysis for the Behavioral Sciences. Hillsdale, NJ: Lawrence Erlbaum Associates; 1988.

41. Mourits MP, Prummel MF, Wiersinga WM, Koornneef L. Clinical activity score as a guide in the management of patients with Graves' ophthalmopathy. Clin Endocrinol. 1997;47(1):9-14. doi:10.1046/ j.1365-2265.1997.2331047.x

42. Dolman PJ. Evaluating Graves' orbitopathy. Best Pract Res Clin Endocrinol Metab. 2012;26(3):229-248. doi:10.1016/j.beem.2011.11.007

43. Bahn RS. Graves' ophthalmopathy. $N$ Engl J Med. 2010;362 (8):726-738. doi:10.1056/NEJMra0905750

44. Douglas RS, Afifiyan NF, Hwang CJ, et al. Increased generation of fibrocytes in thyroid-associated ophthalmopathy. J Clin Endocrinol Metab. 2010;95(1):430-438. doi:10.1210/jc.2009-1614

45. Abràmoff MD, Kalmann R, de Graaf ME, Stilma JS, Mourits MP. Rectus extraocular muscle paths and decompression surgery for Graves orbitopathy: mechanism of motility disturbances. Invest Ophthalmol Vis Sci. 2002;43(2):300-307.

46. Gilbard JP, Farris RL. Ocular surface drying and tear film osmolarity in thyroid eye disease. Acta Ophthalmol (Copenh). 1983;61 (1):108-116. doi:10.1111/j.1755-3768.1983.tb01401.x

47. Khurana AK, Sham S, Ahluwalia BK, Malhotra KC. Tear film profile in Graves' ophthalmopathy. Acta Ophthalmol (Copenh). 1992;70 (3):346-349. doi:10.1111/j.1755-3768.1992.tb08576.x

48. Cruz AAV, Ribeiro SF, Garcia DM, Akaishi PM, Pinto CT. Graves upper eyelid retraction. Surv Ophthalmol. 2013;58(1):63-76. doi:10.1016/j.survophthal.2012.02.007

49. El Annan J, Chauhan SK, Ecoiffier T, Zhang Q, Saban DR, Dana R. Characterization of effector $\mathrm{T}$ cells in dry eye disease. Invest Ophthalmol Vis Sci. 2009;50(8):3802-3807. doi:10.1167/iovs.082417

50. Rocha EM, Mantelli F, Nominato LF, Bonini S. Hormones and dry eye syndrome: an update on what we do and don't know. Curr Opin Ophthalmol. 2013;24(4):348-355. doi:10.1097/ICU.0b013e3283 $6227 \mathrm{bf}$ 
51. Harris MA, Realini T, Hogg JP, Sivak-Callcott JA. CT dimensions of the lacrimal gland in Graves orbitopathy. Ophthalmic Plast Reconstr Surg. 2012;28(1):69-72. doi:10.1097/IOP.0b013e31823c4a3a

52. Moncayo R, Baldissera I, Decristoforo C, Kendler D, Donnemiller E. Evaluation of immunological mechanisms mediating thyroidassociated ophthalmopathy by radionuclide imaging using the somatostatin analog 111In-octreotide. Thyroid. 1997;7(1):21-29. doi:10.1089/thy.1997.7.21
53. Khalil HA, de Keizer RJ, Kijlstra A. Analysis of tear proteins in Graves' ophthalmopathy by high performance liquid chromatography. Am J Ophthalmol. 1988;106(2):186-190. doi:10.1016/00029394(88)90832-X

54. Brasil MV, Brasil OF, Vieira RP, Vaisman M, Amaral Filho OM. Tear film analysis and its relation with palpebral fissure height and exophthalmos in Graves' ophthalmopathy. Arq Bras Oftalmol. 2005;68(5):615-618. doi:10.1590/S0004-27492005000500007
Clinical Ophthalmology

\section{Publish your work in this journal}

Clinical Ophthalmology is an international, peer-reviewed journal covering all subspecialties within ophthalmology. Key topics include: Optometry; Visual science; Pharmacology and drug therapy in eye diseases; Basic Sciences; Primary and Secondary eye care; Patient Safety and Quality of Care Improvements. This journal is indexed on PubMed

Submit your manuscript here: https://www.dovepress.com/clinical-ophthalmology-journal

\section{Dovepress}

Central and CAS, and is the official journal of The Society of Clinical Ophthalmology (SCO). The manuscript management system is completely online and includes a very quick and fair peer-review system, which is all easy to use. Visit http://www.dovepress.com/ testimonials.php to read real quotes from published authors. 